\title{
Reparametrização do modelo baseado na lei de superfície para predição da fração digestível da fibra em detergente neutro em condições brasileiras
}

\section{Edenio Detmann1, Sebastião de Campos Valadares Filho1, Lara Toledo Henriques ${ }^{2}$, Douglas dos Santos Pina ${ }^{3}$, Mário Fonseca Paulino ${ }^{1}$, André Luiz Rodrigues Magalhães ${ }^{4}$, Darcilene Maria de Figueiredo ${ }^{3}$, Marlos de Oliveira Porto ${ }^{3}$, Mário Luiz Chizzotti ${ }^{3}$}

\footnotetext{
${ }^{1}$ Departamento de Zootecnia, Universidade Federal de Viçosa, Viçosa-MG, CEP: 36571-000. Bolsista do CNPq.

2 Pós-Doutoranda, DZO-UFV. Bolsista da CAPES.

${ }^{3}$ Doutorando, DZO-UFV. Bolsista do CNPq.

${ }^{4}$ Universidade Federal Rural de Pernambuco/Unidade Acadêmica de Garanhus (UFRPE/UAG)
}

RESUMO - Objetivou-se avaliar as estimativas da fração digestível da FDN em bovinos com base na aplicação do conceito de Lei de Superfície. Adotou-se a estrutura básica do modelo de predição sugerido pelo sistema nutricional NRC (2001), cujos parâmetros básicos são: fator de proteção da lignina sobre os carboidratos da parede celular vegetal (FPL) e coeficiente de digestibilidade da fração potencialmente digestível da FDN (CDFDNP). Dois diferentes conjuntos de estimativas desses parâmetros foram avaliados. No primeiro caso, denominado Modelo Weiss (MW), empregaram-se 0,75 e 0,667 como estimativas de CDFDNP e FPL, respectivamente. No segundo caso (Modelo Corrigido - MC), adotou-se 0,85 como estimativa de FPL. As estimativas de CDFDNP foram obtidas por meio de meta-análise de dois experimentos conduzidos com vacas em lactação e quatro conduzidos com bovinos em crescimento e terminação, assumindo valores de 0,67 e 0,835 , respectivamente Os procedimentos de comparação entre modelos foram conduzidos sobre dois experimentos, um para cada categoria animal. Para vacas em lactação, verificou-se similaridade entre modelos no tocante ao erro médio de predição (EMP), de $+1,07$ e $+1,05$ pontos percentuais de FDN digestível para MW e MC, respectivamente. Para bovinos em crescimento e terminação, verificou-se menor EMP para MC (+0,42 pontos percentuais) em comparação ao MW (-6,64 pontos percentuais). A direção da flutuação dos erros de predição constituiu a principal limitação de MC, possível reflexo de interferências ambientais sobre a interação carboidratos lignina na parede celular. Embora o MC permita a obtenção de estimativas mais verossímeis que MW, a incorporação de métodos biológicos para estimação da fração potencialmente digestível da FDN pode incrementar a acurácia do processo de predição.

Palavras-chave: lignina, sistema NRC (2001), nutrientes digestíveis totais

\section{Reparameterization of the model based on Surface Law to predict the digestible fraction of neutral detergent fiber in Brazilian cattle}

ABSTRACT - The objective of this study was to evaluate the estimates of the digestible fraction of neutral detergent fiber (NDF) in cattle using the Surface Law approach. The prediction model used in this study was similar to that proposed by the NRC (2001). The following model parameters were used: lignin protection factor on cell wall carbohydrates (LPF) and digestibility coefficient of potentially digestible NDF (DCPNDF). Two estimate sets of these parameters were evaluated. The first set was called Weiss Model (WM) and the estimates were 0.75 and 0.667 for DCPNDF and LPF, respectively. The second set was called Corrected Model (CM) and the estimate of LPF was 0.85. For the CM the estimates of DCPNDF were obtained by meta-analysis of two trials with lactating cows and four trials with growing and finishing cattle $(0.67$ and 0.835 , respectively). Models were compared by using two experiments of each animal category. Both models predicted similar digestible NDF for lactating cows. The mean prediction errors (MPE) were +1.07 and +1.05 percentile points of digestible NDF for WM and CM, respectively. The MPE was lower in CM (+0.42 percentile points) than in WM (-6.64 percentile points) for growing and finishing cattle. The random fluctuation pattern of the prediction errors was the main limitation of the CM, which might be explained by environmental effects on the interaction between carbohydrates and lignin in the plant cell wall. Although the $\mathrm{CM}$ resulted in better estimates than the WM, inclusion of biological methods to estimate potentially digestible NDF may improve the prediction accuracy.

Key Words: lignin, NRC (2001) model, total digestible nutrients 


\section{Introdução}

A obtenção de estimativas de digestibilidade é essencial para se conhecer o valor energético dos alimentos, notadamente via nutrientes digestíveis totais, o que permite o balanceamento adequado de dietas que propiciem o atendimento das demandas para mantença e produção dos animais.

Entre os diferentes componentes dos alimentos, a fração fibrosa é de fundamental importância em sistemas de produção tropicais, pois fornece quantidade significativa de energia a baixo custo e, por apresentar variabilidade naturalmente superior aos demais componentes, deve ocupar posição central na avaliação da disponibilidade de energia (Detmann et al., 2004).

A obtenção da contribuição energética dos diferentes componentes a partir de seus teores nos diferentes alimentos tem sido sugerida por diversos autores (Conrad et al., 1984; Weiss et al., 1992; Van Soest, 1994). Essa proposição visa contornar o ônus de recursos financeiros e de tempo dos tradicionais ensaios de digestão in vivo.

Considerando essa perspectiva, o NRC (2001) adotou um método com esse embasamento para estimação do teor de NDT dos alimentos, o qual constitui sistema de equações somativas. Neste sistema, a cada grupo de compostos químicos, inclusive a fração fibrosa (representada pela FDN), destina-se uma equação para obtenção de estimativas de coeficientes de digestibilidade verdadeiros, com posterior correção quanto ao nível de consumo e, quando pertinente, às perdas metabólicas.

Em contexto específico, a equação destinada à predição da fração digestível da FDN adotada pelo NRC (2001) baseia-se na estimação da fração potencialmente digestível da fibra a partir de sua relação com a lignina (Conrad et al., 1984; Weiss et al., 1992), a qual apresentaria coeficiente de digestibilidade constante em animais alimentados em condições de mantença (NRC, 2001). Contudo, mesmo apresentando fundamentos pressupostamente teóricos e população-independente baseados no conceito geométrico denominado Lei de Superfície (Weiss et al., 1992), essa equação tem conduzido a estimativas da fração digestível dos componentes fibrosos não-condizentes com observações in vivo (Rocha Jr. et al., 2003; Campos, 2004; Oliveira, 2005; Pina, 2005). Segundo observações verificadas em condições brasileiras, parte deste viés parece estar associada a diferenças na interação lignina $\times$ carboidratos da parede celular vegetal de alimentos produzidos em condições tropicais em relação àqueles produzidos em condições temperadas (Detmann et al., 2004).
No entanto, segundo Detmann et al. (2004), a estrutura matemática do modelo adotado pelo NRC (2001) para predição da fração digestível da FDN poderia ser utilizada em condições tropicais, havendo, contudo, necessidade de ajustamento de seus parâmetros para estas condições.

Dessa forma, objetivou-se neste estudo estimar a fração digestível da FDN na dieta de bovinos a partir do modelo adotado pelo NRC (2001), propondo-se, em adição, correções das estimativas dos parâmetros adotados nesse modelo a partir de observações obtidas em condições tropicais.

\section{Material e Métodos}

Para a avaliação da fração digestível da FDN, adotou-se estrutura de modelo proposta por Conrad et al. (1984) e Weiss et al. (1992), representada por:

$F D N d=\beta_{1} \times\left\{(F D N c p-L) \times\left[1-\left(\frac{L}{F D N c p}\right)^{\beta_{2}}\right]\right\}$

em que: $\mathrm{FDNd}=$ teor de fibra em detergente neutro digestível (\% da MS); FDNcp = teor de FDN corrigida para cinzas (matéria mineral) e proteína (compostos nitrogenados) (\% da MS); $\mathrm{L}=$ teor de lignina (\% da MS), estimado via método do ácido sulfúrico (Van Soest \& Robertson, 1985); $\beta_{1}=$ coeficiente de digestibilidade da fração potencialmente digestível da FDN; e $\beta_{2}=$ fator de proteção à degradação ruminal sobre os carboidratos fibrosos inerente à ação da lignina.

Antecipa-se que, embora o modelo original contemple apenas a correção para o teor de compostos nitrogenados da FDN (NRC, 2001), a correção para matéria mineral foi incorporada neste trabalho em virtude da possibilidade de subestimação do teor de CNF e superestimação da fração com potencial para contribuição energética da FDN, caso não fosse considerada.

As correções dos compostos nitrogenados e da matéria mineral sobre a FDN foram realizadas conforme recomendações de Licitra et al. (1996) e Mertens (2002), respectivamente.

O complemento da estrutura do modelo descrito em (1) foi realizado de duas formas diferentes, denominadas Modelo Weiss e Modelo Corrigido.

No primeiro caso, a qual equivale à forma sugerida inicialmente por Weiss et al. (1992) e adotada com modificações pelo NRC (2001), admitiu-se como estimativa do parâmetro $\beta_{2}$ o valor $2 / 3$ ou 0,667 . Essa estimativa é derivada do conceito geométrico de sólidos denominado Lei de Superfície, no qual afirma-se que a superfície de qualquer objeto é igual ao quadrado da média de suas dimensões 
lineares ou à sua massa elevada à potência de $2 / 3$ (Kleiber, 1975; Conrad et al., 1984), pressupondo-se que o espaço de superfície digestível e disponível aos microrganismos ruminais é determinado pelo fato de os carboidratos e o complexo lignina da parede vegetal estarem localizados fisicamente superfície a superfície.

Por sua vez, o coeficiente de digestibilidade da fração potencialmente digestível da FDN $\left(\beta_{1}\right)$ adotado para o Modelo Weiss origina-se dos conceitos de interação cinéticas de trânsito $\times$ degradação ruminal (Waldo et al., 1972), assumindo, a partir de aproximação empírica (Weiss et al., 1992), a forma:

$\hat{\beta}_{1}=\frac{k d}{k d+k p} \cong 0,75$

em que: $k d$ e $k p=$ taxas fracionais de degradação e passagem para a fração potencialmente digestível da FDN $\left(\mathrm{h}^{-1}\right)$; e $\hat{\beta}_{1}$ estimativa para o coeficiente de digestibilidade da fração potencialmente digestível da FDN .

Dessa forma, o Modelo Weiss assume a estrutura:

$F D N d=0,75 \times\left\{(F D N c p-L) \times\left[1-\left(\frac{L}{F D N c p}\right)^{0,667}\right]\right\}$

Para a estruturação do Modelo Corrigido, adotou-se como estimativa do parâmetro $\beta_{2}$ o valor 0,85 , derivado empiricamente por Detmann et al. (2004) a partir de observações sobre a relação lignina $\times$ teor da fração indigestível da FDN (FDNi) em gramíneas tropicais.

A estimativa do parâmetro $\beta_{1}$, no entanto, foi obtida pela análise de quatro experimentos conduzidos com bovinos em crescimento e terminação - dois em ambiente de confinamento (Guimarães, 2005) e dois em pastejo (Figueiredo, 2005; Porto, 2005) - e dois conduzidos com vacas em lactação em confinamento (Guimarães, 2005; Pina et al., 2006). Em todos os experimentos, a alimentação foi fornecida ad libitum aos animais.

Os coeficientes de digestibilidade da fração potencialmente digestível da FDN foram obtidos por meio da equação:

$C D F D N P=\frac{C_{F D N P}-E F_{F D N P}}{C_{F D N P}}=1-\frac{E F_{F D N P}}{C_{F D N P}}=1-\frac{C_{F D N}-C_{F D N i}}{E F_{F D N}-E F_{F D N i}}(4)$; em que: $\mathrm{CDFDNP}=$ coeficiente de digestibilidade da fração potencialmente digestível da FDN; $\mathrm{C}_{\mathrm{FDNP}}=$ consumo de FDN potencialmente digestível ( $\mathrm{kg} / \mathrm{dia}) ; \mathrm{EF}_{\mathrm{FDNP}}=$ excreção fecal de FDN potencialmente digestível ( $\mathrm{kg} / \mathrm{dia}) ; \mathrm{C}_{\mathrm{FDN}}=$ consumo de FDN (kg/dia); $\mathrm{EF}_{\mathrm{FDN}}=$ excreção fecal de FDN (kg/dia); $\mathrm{C}_{\mathrm{FDNi}}=$ consumo de FDNi (kg/dia); e $\mathrm{EF}_{\mathrm{FDNi}}=$ excreção fecal de FDNi (kg/dia).

Os teores dietéticos e fecais de FDNi foram estimados por procedimentos de incubação in situ por 144 horas. Para o cálculo do CDFDNP, assumiu-se igualdade entre consumo e excreção fecal de FDNi (Detmann et al., 2007).
Os experimentos com bovinos em crescimento e terminação realizados por Guimarães (2005) e Porto (2005) foram conduzidos segundo delineamento em quadrado latino $4 \times 4$. O experimento realizado por Figueiredo (2005), por sua vez, foi conduzido segundo delineamento em quadadro latino 5 x 5 incompleto, com ausência do último período experimental. Ambos os experimentos realizados com vacas em lactação foram conduzidos em delineamento em quadrado latino $4 \times 4$, com triplicatas para os quadrados, organizados segundo o nível de produção dos animais.

As estimativas obtidas foram avaliadas por meio de análise de variância conjunta em esquema de meta-análise, segundo os modelos, para bovinos em crescimento e terminação e para vacas em lactação, respectivamente:

$$
\begin{aligned}
& Y_{i j k l}=\mu+C_{i j k l}+E_{i}+T_{(i) j}+A_{(i) k}+P_{(i) l}+\left(C_{i j k l} \times E_{i}\right)+\varepsilon_{i j k l} \\
& Y_{i j k m}=\mu+C_{i j k l m}+E_{i}+Q_{(i) j}+T_{(i) k}+A_{(i j) l}+P_{(i j) m}+Q T_{(i) j k}+\left(C_{i j k m} \times E_{i}\right)+\varepsilon_{i j k l m m}
\end{aligned}
$$

para o modelo (5): $\mathrm{Y}_{\mathrm{ijkl}}=$ resposta experimental; $\mu=$ constante geral; $\mathrm{C}_{\mathrm{ijkl}}=$ efeito da variável contínua consumo de MS ( $g / k g$ de PV); $E_{i}=$ efeito relativo ao experimento i; $\mathrm{T}_{(\mathrm{i}) \mathrm{j}}=$ efeito relativo ao tratamento $\mathrm{j}$, aninhado ao experimento i; $\mathrm{A}_{(\mathrm{i}) \mathrm{k}}=$ efeito relativo ao animal $\mathrm{k}$, aninhado ao experimento $\mathrm{i} ; \mathrm{P}_{(\mathrm{i}) 1}=$ efeito relativo ao período 1 , aninhado ao experimento $\mathrm{i} ;\left(\mathrm{C}_{\mathrm{ijkl}} \mathrm{x} \mathrm{E}_{\mathrm{i}}\right)=$ efeito da interação consumo $\times$ experimento; e $\varepsilon_{\mathrm{ijkl}}=$ erro aleatório, não-observável, pressuposto normal e independentemente distribuído, com média 0 e variância $\sigma^{2}$; para o modelo (6): $Y_{\mathrm{ijklm}}=$ resposta experimental; $\mu=$ constante geral; $\mathrm{C}_{\mathrm{ijklm}}=$ efeito da variável contínua consumo de matéria seca ( $\mathrm{g} / \mathrm{kg}$ de $\mathrm{PV}) ; \mathrm{E}_{\mathrm{i}}=$ efeito relativo ao experimento $\mathrm{i} ; \mathrm{Q}_{(\mathrm{i}) \mathrm{j}}=$ efeito relativo ao quadrado latino $\mathrm{j}$, aninhado ao experimento $\mathrm{i} ; \mathrm{T}_{(\mathrm{i}) \mathrm{k}}=$ efeito relativo ao tratamento $\mathrm{k}$, aninhado ao experimento $\mathrm{i}$; $\mathrm{A}_{(\mathrm{ij}) 1}=$ efeito relativo ao animal 1 , aninhado ao efeitos de experimento i e quadrado latino $\mathrm{j} ; \mathrm{P}_{(\mathrm{ij}) \mathrm{m}}=$ efeito relativo ao período $\mathrm{m}$, aninhado ao efeitos de experimento i e quadrado latino $\mathrm{j} ; \mathrm{QT}_{(\mathrm{i}) \mathrm{jk}}=$ efeito de interação quadrado latino $\mathrm{j} \times$ tratamento $\mathrm{k}$, aninhado ao experimento $\mathrm{i} ;\left(\mathrm{C}_{\mathrm{ijklm}} \mathrm{xE}_{\mathrm{i}}\right)=$ efeito da interação consumo $\times$ experimento; e $\varepsilon_{\mathrm{ijklm}}=$ erro aleatório, não-observável, pressuposto normal e independentemente distribuído, com média 0 e variância $\sigma^{2}$.

A variável contínua consumo voluntário de MS foi incluída nos modelos no intuito de verificar a possível relação entre consumo e coeficiente de digestibilidade.

Anteriormente à análise, procedeu-se à avaliação da homogeneidade das variâncias residuais entre experimentos para cada categoria animal por meio do teste de Bartlett (Snedecor \& Cochran, 1989), sendo verificada condição de homocedasticidade $(\mathrm{P}>0,05)$. Em virtude da diferença entre 
delineamentos para os experimentos com bovinos em crescimento e terminação e da perda de duas observações em cada experimento com vacas em lactação, as análises foram conduzidas utilizando-se somas de quadrados do tipo III, sendo as médias estimadas por procedimentos de quadrados mínimos. Todos os procedimentos estatísticos foram conduzidos por meio do programa SAS (Statistical Analysis System) (Littell et al., 1991), adotando-se 0,05 como nível crítico de probabilidade para o erro tipo I.

Neste contexto, o Modelo Corrigido assume a estrutura:

$$
F D N d=\hat{\beta}_{1} \times\left\{(F D N c p-L) \times\left[1-\left(\frac{L}{F D N c p}\right)^{0,85}\right]\right\}
$$

sendo todos os termos definidos anteriormente.

Para comparação entre os teores dietéticos de FDN digestível estimados por ambos os modelos, foram utilizados dados obtidos de um experimento conduzido com bovinos em crescimento (Silva, 2004) e de um com vacas em lactação (Chizzotti, 2004).

No experimento desenvolvido por Silva (2004), foram utilizados quatro novilhos com grau de sangue predominantemente Holandês e peso médio de $320 \mathrm{~kg}$. O experimento constou de cinco períodos experimentais de 15 dias, sendo os animais mantidos confiados em baias individuais. A dieta oferecida foi composta exclusivamente por capim-elefante, fornecido ad libitum, em média, aos 33, 48, 63, 78 e 93 dias de rebrotação. Em cada período experimental, os animais foram alimentados com o capim em um único período de rebrotação. Verificou-se a perda de uma unidade experimental, totalizando 19 observações para o experimento.

No experimento desenvolvido por Chizzotti (2004), foram utilizadas 15 vacas holandesas lactantes, manejadas em sistema de confinamento tipo tie stall, alimentadas ad libitum com silagem de milho, com suplementação concentrada na relação de $1 \mathrm{~kg}$ para cada $3 \mathrm{~kg}$ de leite produzido. Os animais foram organizados em grupos de cinco, equivalentes aos níveis alto $(32,6 \mathrm{~kg} / \mathrm{dia})$, médio $(18,5 \mathrm{~kg} / \mathrm{dia})$ e baixo $(5,9 \mathrm{~kg} / \mathrm{dia})$ de produção de leite, cujas proporções finais de volumoso na ração, com base na MS, foram $55,9,68,0 \mathrm{e} 84,7 \%$, respectivamente. Oexperimento foi conduzido segundo delineamento inteiramente casualizado, totalizando 15 observações.

Os teores de NDT foram preditos, em cada experimento, segundo proposições do NRC (2001). Desta forma, os teores de FDN digestível obtidos pelo Modelo Weiss, relacionados a consumo em nível de mantença (NRC, 2001), foram corrigidos quanto ao nível de consumo para o experimento conduzido por Chizzotti (2004), segundo procedimentos descritos pelo NRC (2001), considerando o consumo médio experimental como de 2,5 vezes o requerido para mantença. Para o experimento conduzido por
Silva (2004), nenhuma correção quanto ao nível de consumo foi realizada, visto que os valores preditos para os teores de NDT mantiveram-se abaixo do limite de $57,2 \%$ (NRC, 2001).

A avaliação comparativa da eficiência de predição entre modelos foi realizada, para cada experimento, por meio da avaliação e partição do quadrado médio dos erros de predição (QMEP), segundo protocolos descritos por Kobayashi \& Salam (2000), conforme as equações:

$$
Q M E P=Q V+M a F+M o F=\frac{1}{n} \sum_{i=1}^{n}\left(x_{i}-y_{i}\right)^{2}
$$

$Q V=(\bar{x}-\bar{y})^{2}$

$M a F=\left(s_{x}-s_{y}\right)^{2}$

$M o F=2 s_{x} s_{y}(1-r)$

em que: $\mathrm{x}=$ valores preditos; $\mathrm{y}=$ valores observados; $\mathrm{QMEP}=$ quadrado médio dos erros de predição; $\mathrm{QV}=$ quadrado do vício; $\mathrm{MaF}=$ componente relativo à magnitude de flutuação aleatória; MoF = componente relativo ao modelo de flutuação alatória; $\mathrm{s}_{\mathrm{x}}$ e $\mathrm{s}_{\mathrm{y}}=$ desvios-padrão para valores preditos e observados, respectivamente; $\mathrm{e} r=$ correlação linear de Pearson entre valores preditos e observados.

Ressalta-se que, por se tratar de avaliação de erro de predição, para todos os cálculos de variâncias e covariâncias, empregou-se como divisor o total de observações (n) (Kobayashi \& Salam, 2000).

\section{Resultados e Discussão}

Na Tabela 1 são apresentados os resultados obtidos para as análises conjuntas de experimentos das variáveis coeficiente de digestibilidade da FDN potencialmente digestível (CDFDNP) e consumo voluntário de MS (CMS).

A avaliação realizada sobre bovinos em crescimento e terminação indicou ausência de efeito $(P>0,05)$ de qualquer uma das variáveis incluídas no modelo (Equação 5) sobre o CDFDNP, mesmo com diferenças no tocante ao CMS entre experimentos, animais e períodos experimentais $(\mathrm{P}<0,05)$. Desta forma, garantiu-se a expressão do CDFDNP por intermédio de uma estimativa única (aproximadamente 0,835 ) (Tabela 2), independentemente de situação experimental ou produtiva.

A ausência de relação entre CMS e CDFDNP $(\mathrm{P}>0,05)$ diverge aparentemente da definição de relação inversamente proporcional entre consumo e digestibilidade em ruminantes (Merchen, 1988). Contudo, as estimativas de coeficiente de digestibilidade relatadas neste estudo referem-se a uma fração específica da FDN, a qual não necessariamente converge às estimativas de coeficiente de digestibilidade 
da FDN total, que sofrem ainda influências de interações específicas das dinâmicas de degradação e passagem sobre o efeito de repleção ruminal total da fibra e da dimensão da fração indigestível da FDN (Waldo et al., 1972; Vieira et al., 1997).

Por outro lado, a projeção dos limites do intervalo de confiança com $95 \%$ de probabilidade para o CDFDNP verificado em bovinos em crescimento e terminação (Tabela 1) permite inferir que sua estimativa é superior $(\mathrm{P}<0,05)$ ao valor descrito por Weiss et al. (1992). Esta diferença, no entanto, se torna nutricionalmente mais relevante pelo fato de a estimativa obtida neste estudo referir-se a condições de alimentação ad libitum, contrariamente à condição estudada por Weiss et al. (1992), o qual projetou suas proposições a animais sob restrição alimentar (mantença).

Essa divergência pode ser suportada, ao menos em parte, no maior tempo de retenção ruminal de partículas fibrosas de forragens tropicais em comparação àquelas produzidas em condições temperadas, implicando maior tempo de exposição à degradação ruminal, resultando, conseqüentemente, em maior digestibilidade total.

O maior tempo de retenção ruminal de forragens tropicais em comparação às temperadas baseia-se, em grande parte, na disposição física dos compostos fenólicos na parede celular. Menor proporção de lignina em conformação core é verificada em forragens tropicais (Van Soest, 1994), resultando, comparativamente, em menor concentração dos compostos fenólicos na parede primária e em maior nível de ramificação de compostos fenólicos não-core sobre o restante da parede celular, incorrendo em menor velocidade de degradação da fração potencialmente degradável da FDN (Jung \& Deetz, 1993), embora com menor proporção de FDN indigestível por unidade de lignina (Detmann et al., 2004). Dessa forma, amplia-se o tempo necessário para o alcance de faixa de densidade específica que habilita a partícula ao escape ruminal, implicando elevação da degradação efetiva da fração potencialmente digestível da FDN.

Verificou-se, no entanto, influência de experimento, de quadrado latino, de animal e de período experimental $(\mathrm{P}<0,05)$ sobre o CDFDNP em vacas em lactação (Tabela 1 ), contrariando os resultados obtidos para bovinos em crescimento e terminação. Considerando a limitação do banco de dados disponível neste estudo para esta categoria animal, relações definidas não puderam ser construídas para obtenção de estimativas mais acuradas desta variável. Portanto, com base na ausência de relação com a variável CMS e nos efeitos de experimento, tratamentos e interação CMS $\times$ experimento $(\mathrm{P}>0,05)$ (Tabela 1), optou-se por estabelecer estimativa única para construção do modelo, com valor aproximado de 0,67 (Tabela 2).

Segundo relatos de Costa et al. (2005), a relação entre coeficientes de digestibilidade obtidos em bovinos em condições tropicais sob alimentação não-restrita (produção) e restrita (mantença) aproxima-se de 0,95. Desse modo, estimou-se CDFDNP para vacas sob alimentação restrita

Tabela 1 - Níveis descritivos de probabilidade para o erro tipo I associado às diferentes hipóteses de nulidade e coeficientes de variação (CV) para o coeficiente de digestibilidade da fibra em detergente neutro potencialmente digestível (CDFDNP) e o consumo voluntário de MS (CMS - g/kg de peso vivo) para bovinos em crescimento e terminação e vacas em lactação

Table 1 - Descriptive levels of probability of type I error for different null hypotheses and coefficients of variation (CV) for the digestibility coefficient of potentially digestible NDF (DCPNDF) and voluntary DM intake (DMI-g/kg of body weight) for growing and finishing cattle and lactating cows

\begin{tabular}{|c|c|c|c|c|}
\hline \multirow[t]{3}{*}{$\begin{array}{l}\text { Efeito }{ }^{1} \\
\text { Effect }\end{array}$} & \multicolumn{4}{|c|}{$\begin{array}{l}\text { Categoria animal } \\
\text { Animal category }\end{array}$} \\
\hline & \multicolumn{2}{|c|}{$\begin{array}{c}\text { Bovinos em crescimento e terminação } \\
\text { Growing and finishing cattle }\end{array}$} & \multicolumn{2}{|c|}{$\begin{array}{l}\text { Vacas em lactação } \\
\text { Lactating cows }\end{array}$} \\
\hline & $\begin{array}{l}\text { CDFDNP } \\
P N D F D C\end{array}$ & $\begin{array}{l}\text { CMS } \\
D M I\end{array}$ & $\begin{array}{l}\text { CDFDNP } \\
P N D F D C\end{array}$ & $\begin{array}{l}\text { CMS } \\
D M I\end{array}$ \\
\hline CMS $(D M I)$ & 0,8110 & - & 0,2923 & - \\
\hline EXP & 0,7867 & $<0,0001$ & 0,3564 & $<0,0001$ \\
\hline $\mathrm{QL}(L Q)$ & - & - & 0,0018 & $<0,0001$ \\
\hline TRAT (TREAT) & 0,9728 & 0,3181 & 0,4608 & 0,0018 \\
\hline ANIM & 0,4175 & $<0,0001$ & 0,0001 & $<0,0001$ \\
\hline PER & 0,2895 & $<0,0001$ & 0,0072 & $<0,0001$ \\
\hline QLXTRAT (LQxTREAT) & - & - & 0,5676 & 0,1310 \\
\hline CMSXEXP (DMIxEXP) & 0,8002 & - & 0,4632 & - \\
\hline $\mathrm{CV}(\%)$ & 3,9 & 4,2 & 6,2 & 3,8 \\
\hline
\end{tabular}

${ }^{1} \mathrm{CMS}=$ consumo voluntário de MS; EXP = experimento; $\mathrm{QL}=$ quadrado latino; TRAT = tratamento; ANIM = animal; PER = período; QLxTRAT = interação quadrado latino $x$ tratamento; CMS $\times$ EXP = interação consumo voluntário de MS $\times$ experimento. Para maiores detalhes, consultar equações (5) e (6). ${ }^{1} \mathrm{DMI}=$ voluntary $D M$ intake; $E X P=$ experiment; $L Q=$ Latin square; TREAT = treatment; $A N I M=$ animal; $P E R=$ period; $L Q x T R E A T=L$ atin square $x$ treatment interaction; $D M I \times E X P=$ voluntary dry matter intake x experiment interaction. For more details, see equations (5) and (6). 
Tabela 2 - Médias de quadrados mínimos para o coeficiente de digestibilidade da fibra em detergente neutro potencialmente digestível (CDFDNP) e consumo voluntário de MS (CMS - g/kg de peso vivo) para bovinos em crescimento e terminação e vacas em lactação, em função dos experimentos avaliados

Table 2 - $\quad$ Least square means for the digestibility coefficient of potentially digestible NDF (DCPNDF) and voluntary DM intake (DMI - g/kg of body weight) for growing and finishing cattle and lactating cows

\begin{tabular}{|c|c|c|c|c|}
\hline \multirow[t]{3}{*}{$\begin{array}{l}\text { Experimento } \\
\text { Experiment }\end{array}$} & \multicolumn{4}{|c|}{$\begin{array}{l}\text { Categoria animal } \\
\text { Animal category }\end{array}$} \\
\hline & \multicolumn{2}{|c|}{$\begin{array}{c}\text { Bovinos em crescimento e terminação }{ }^{1} \\
\text { Growing and finishing cattle }\end{array}$} & \multicolumn{2}{|c|}{$\begin{array}{l}\text { Vacas em lactação }{ }^{2} \\
\text { Lactating cows }\end{array}$} \\
\hline & $\begin{array}{l}\text { CDFDNP } \\
P N D F D C\end{array}$ & $\begin{array}{l}\text { CMS } \\
D M I\end{array}$ & $\begin{array}{l}\text { CDFDNP } \\
P N D F D C\end{array}$ & $\begin{array}{l}\text { CMS } \\
D M I\end{array}$ \\
\hline 1 & 0,8389 & 19,73 & 0,6318 & 29,93 \\
\hline 2 & 0,8445 & 21,29 & 0,7139 & 33,05 \\
\hline 3 & 0,8003 & 23,92 & - & - \\
\hline 4 & 0,8614 & 22,68 & - & - \\
\hline Geral (Overall) ${ }^{3}$ & 0,8346 & 21,78 & 0,6698 & 31,46 \\
\hline $\mathrm{LS}(H L)$ & 0,8491 & - & 0,6856 & - \\
\hline $\mathrm{LI}(L L)$ & 0,8201 & - & 0,6540 & - \\
\hline
\end{tabular}

1 Exp. 1 = Figueiredo (2005); Exp. 2 = Porto (2005); Exp. 3 e Exp.4 = Guimarães (2005).

2 Exp. 1 = Guimarães (2005); Exp. 2 = Pina (2005).

3 LS e LI = limites superior e inferior do intervalo de confiança com 95\% de probabilidade para a média geral $(H L$ and $L L=$ higher and lower limits of confidence interval with $95 \%$ of probability for the overall mean).

(mantença) a partir da estimativa geral (Tabela 1 ), de 0,705 , que se aproxima do valor relatado por Weiss et al. (1992).

De outra forma, a superioridade da estimativa de CDFDNP obtida em animais em crescimento e terminação, em comparação a vacas em lactação, pode estar suportada no maior CMS e nos maiores níveis de concentrado na dieta verificados normalmente para vacas em lactação. Maior CMS resulta diretamente em maior taxa de passagem (AFRC, 1993), reduzindo o tempo de exposição à degradação microbiana e, conseqüentemente, a digestibilidade total. Por outro lado, a elevação do nível de concentrado na dieta provoca maior competição de nutriente, menores valores de $\mathrm{pH}$ ruminal e alterações na prioridade de utilização de substratos pelos microrganismos do rúmen, implicando redução na degradação dos componentes fibrosos (Mould et al., 1983; Arroquy et al., 2005).

A atribuição das diferenças no nível de consumo como uma das causas das divergências entre as estimativas de CDFDNP entre categorias animais contraria aparentemente a ausência de relação $(\mathrm{P}>0,05)$ entre esta variável e o consumo observada nas análises de variância conduzidas (Tabela 1).

Contudo, as divergências quanto às estimativas de CMS dentro de cada categoria animal foram significativamente inferiores à verificada entre categorias (Tabela 2). Sugere-se, então, que a influência relativa ao nível de consumo sobre o CDFDNP possa ser suprimida quando as categorias bovinos em crescimento e terminação e vacas em lactação forem avaliadas independentemente, justificando a adoção de estimativas pontuais independentes e diferenciadas de CDFDNP para cada categoria animal.

Definiu-se, portanto, o Modelo Corrigido de forma completa em condições de alimentação irrestrita (produção) por meio das equações:

$$
\begin{aligned}
& F D N d_{C \& T}=0,835 \times\left\{(F D N c p-L) \times\left[1-\left(\frac{L}{F D N c p}\right)^{0,85}\right]\right\} \\
& F D N d_{V L}=0,67 \times\left\{(F D N c p-L) \times\left[1-\left(\frac{L}{F D N c p}\right)^{0,85}\right]\right\}
\end{aligned}
$$

em que: $F_{D N d} d_{C \& T}$ e $F_{D N d} d_{V L}=$ fração efetivamente digestível da FDN para bovinos em crescimento e terminação e vacas em lactação, respectivamente (\% da MS); sendo os demais termos definidos anteriormente.

Como a dimensão da fração potencialmente digestível da FDN constitui uma característica única e exclusiva do substrato (Ørskov, 2000), verifica-se que alterações sobre a fração efetivamente digerida da FDN podem ser oriundas somente de alterações sobre o CDFDNP. Empregando a relação de digestibilidade entre situações de alimentação não-restritas e restritas descrita por Costa et al. (2005), obtêm-se as equações para estimação do teor de FDN digestível em condições de mantença:

$$
\begin{aligned}
& F D N d_{C \& T(m)}=0,879 \times\left\{(F D N c p-L) \times\left[1-\left(\frac{L}{F D N c p}\right)^{0,85}\right]\right\} \\
& F D N d_{V L(m)}=0,705 \times\left\{(F D N c p-L) \times\left[1-\left(\frac{L}{F D N c p}\right)^{0,85}\right]\right\}
\end{aligned}
$$

em que: $\mathrm{FDNd}_{\mathrm{C} \& \mathrm{~T}(\mathrm{~m})}$ e $\mathrm{FDNd}_{\mathrm{VL}(\mathrm{m})}=$ fração digestível da FDN para bovinos em crescimento e terminação e vacas em condições de alimentação restrita (mantença), respecti- 
vamente (\% da MS); sendo os demais termos definidos anteriormente.

Ressalta-se que a falta de distinção entre categorias animais pode constituir limitação à aplicação do modelo proposto por Weiss et al. (1992), fato verificado sobre outros componentes dos alimentos (Detmann et al., 2006a, b, c).

A avaliação comparativa da eficiência de predição para os Modelos Weiss e Corrigido para vacas em lactação está descrita na Tabela 3. Verificou-se similaridade entre modelos quanto à dimensão do erro médio de predição e à partição dos componentes do QMEP em seus diferentes componentes. De modo geral, ambos os modelos foram eficientes em predizer o teor de FDN digestível, o que pode ser confirmado pela baixa dispersão dos erros de predição (Tabela 3; Figura 1).

A similaridade entre modelos parece ser reflexo de um contrabalanceamento entre as estimativas de CDFDNPe do fator de proteção da lignina sobre os carboidratos da parede celular. Enquanto a aplicação do fator de proteção 0,85 para o Modelo Corrigido amplia a estimativa da fração potencialmente digestível da FDN (Detmann et al., 2004), a adoção do CDFDNP de 0,67 reduz a utilização desta mesma fração. No entanto, uma vez que o fator de proteção 0,85 foi proposto (Detmann et al., 2004) e validado (Nunes et al., 2004a) em condições nacionais e que o CDFDNP foi obtido a partir de dados obtidos em condições brasileiras, pode-se inferir que o Modelo Corrigidoé mais confiável e verossímil que o Modelo Weiss.

Por outro lado, verificou-se elevação substancial na capacidade de predição do Modelo Corrigido em comparação ao Modelo Weiss para bovinos em crescimento (Tabela 4; Figura 2), cujos erros médios de predição foram de $+0,42$ e $-6,64$ pontos percentuais respectivamente. Ressalta-se que a redução do erro médio de predição verificada para o Modelo Corrigido calcou-se, quase com exclusividade, sobre o componente relativo ao vício de predição $(\mathrm{QV})$, ressaltando novamente deficiência ao Modelo Weiss em função da não-contemplação de possíveis diferenças entre categorias animais, o que permite suportar, de forma mais efetiva, maior verossimilhança das estimativas obtidas pelo Modelo Corrigido em vacas em lactação, apesar da similaridade entre estimativas verificada para esta categoria animal (Tabela 3).

Independentemente da categoria animal avaliada, ressalta-se o comportamento similar entre os Modelos Weiss e Corrigido quanto aos componentes relativos à magnitude de flutuação (MaF) ao modelo de flutuação (MoF) dos erros de predição (Tabelas 3 e 4).
Tabela 3 - Médias, desvios-padrão (s), erro médio de predição (EMP), quadrado médio do erro de predição (QMEP), quadrado do vício $(\mathrm{QV})$, componente de magnitude de flutuação aleatória (MaF), componente de modelo de flutuação aleatória (MoF) e distribuição dos erros de predição para os teores dietéticos de FDN digestível (\% da MS) em vacas em lactação $(n=15)$

Table 3 - $\quad$ Means, standard deviation(s), mean prediction error(MPE), mean square of prediction error (MSPE), component for magnitude of random fluctuation $(\mathrm{MaF})$, componentformodel of randomfluctuation (MoF) and distribution of prediction errors for dietary contents of DNDF (\% of DM) in lactating cows $(n=15)$

\begin{tabular}{|c|c|c|c|}
\hline \multirow[b]{2}{*}{$\begin{array}{l}\text { Item } \\
\text { Item }\end{array}$} & \multirow[t]{2}{*}{$\begin{array}{c}\text { Valor observado } \\
\text { Observed value }\end{array}$} & \multicolumn{2}{|c|}{$\begin{array}{l}\text { Valor predito } \\
\text { Predicted value }\end{array}$} \\
\hline & & $\begin{array}{c}\text { Modelo } \\
\text { Weiss } \\
\text { Weiss model }\end{array}$ & $\begin{array}{c}\text { Modelo } \\
\text { Corrigido } \\
\text { Corrected model }\end{array}$ \\
\hline Média (Mean) & 20,15 & 21,22 & 21,19 \\
\hline $\mathrm{s}$ & 4,96 & 2,78 & 2,75 \\
\hline $\operatorname{EMP}(M P E)$ & - & 1,07 & 1,05 \\
\hline QMEP (MSPE) & - & 8,63 & 8,78 \\
\hline $\mathrm{QV}(S B)$ & - & 1,15 & 1,10 \\
\hline $\mathrm{MaF}$ & - & 4,79 & 4,91 \\
\hline MoF & - & 2,69 & 2,77 \\
\hline
\end{tabular}

Distribuição acumulada

dos erros de predição $(\%)^{1}$

Cumulative distribution

of prediction errors (\%)

$\leq 1 \mathrm{~s}$

$\leq 2 \mathrm{~s}$

$\leq 3 \mathrm{~s}$

\begin{tabular}{lc}
100 & 100 \\
100 & 100 \\
100 & 100 \\
\hline darddeviation ofobserved values).
\end{tabular}

Distribuição calculada com base no desvio-padrão para os valores

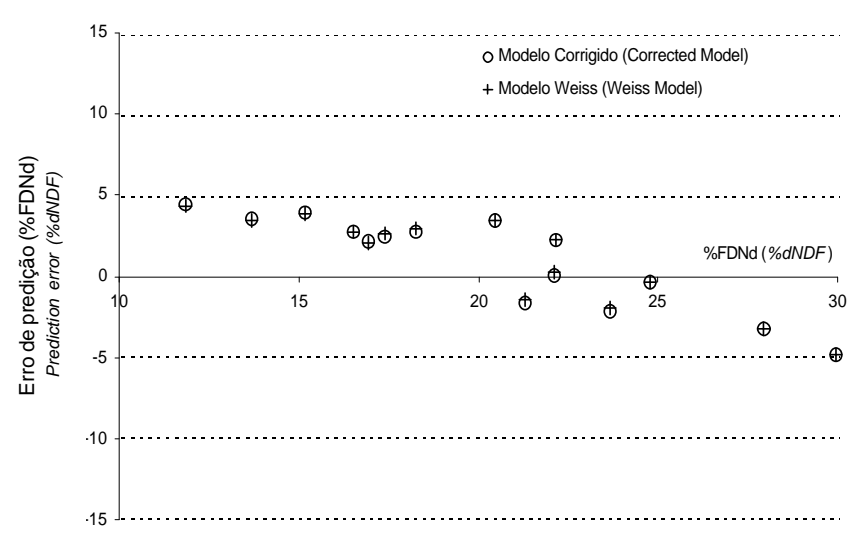

Figura 1 - Distribuição dos erros de predição (pontos percentuais) em função dos teores observados de FDN digestível (FDNd - \% da MS) para vacas em lactação (As linhas tracejadas indicam o afastamento em número de desvios-padrão calculados sobre os valores observados; $n=15$ ).

Figure 1 - Distribution of prediction errors (percentpoints) according to the observed contents of digestible NDF (dNDF - \% of dry matter) for lactating cows (The dashed lines indicate the distance in standard deviations from the observed values; $n=15$ ). 
Tabela 4 - Médias, desvios-padrão (s), erro médio de predição (EMP), quadrado médio do erro de predição (QMEP), quadrado do vício (QV), componente de magnitude de flutuação aleatória (MaF), componente de modelo de flutuação aleatória (MoF) e distribuição dos erros de predição para os teores dietéticos de FDN digestível (\% da MS) em bovinos em crescimento $(n=19)$

Table 4 - $\quad$ Means, standard deviation (s), mean prediction error (MPE), mean square of prediction error (MSPE), component for magnitude of random fluctuation (MaF), component for mode of random fluctuation (MoF) and distribution of prediction errors for dietary contents of DNDF (\% of DM) in growing cattle $(n=19)$

\begin{tabular}{|c|c|c|c|}
\hline \multirow[b]{2}{*}{$\begin{array}{l}\text { Item } \\
\text { Item }\end{array}$} & \multirow[t]{2}{*}{$\begin{array}{c}\text { Valor observado } \\
\text { Observed value }\end{array}$} & \multicolumn{2}{|c|}{$\begin{array}{l}\text { Valor predito } \\
\text { Predicted value }\end{array}$} \\
\hline & & $\begin{array}{c}\text { Modelo } \\
\text { Weiss } \\
\text { Weiss model }\end{array}$ & $\begin{array}{c}\text { Modelo } \\
\text { Corrigido } \\
\text { Corrected model }\end{array}$ \\
\hline Média (Mean) & 38,84 & 32,20 & 39,27 \\
\hline $\mathrm{s}$ & 2,34 & 2,28 & 2,76 \\
\hline $\operatorname{EMP}(M P E)$ & - & $-6,64$ & $+0,42$ \\
\hline QMEP (MSPE) & - & 58,91 & 18,29 \\
\hline $\mathrm{QV}(S B)$ & - & 44,11 & 0,18 \\
\hline $\mathrm{MaF}$ & - & 0,00 & 0,17 \\
\hline MoF & - & 14,80 & 17,94 \\
\hline
\end{tabular}

Distribuição acumulada dos

erros de predição $(\%)^{1}$

Cumulative distribution of

prediction errors (\%)

\begin{tabular}{llll}
\hline$\leq 1 \mathrm{~s}$ & - & 21,1 & 26,3 \\
$2 \mathrm{~s}$ & - & 52,6 & 84,2 \\
$\leq 3 \mathrm{~s}$ & - & 57,9 & 94,7 \\
\hline
\end{tabular}

${ }^{1}$ Distribuição calculada com base no desvio-padrão para os valores observados (The distribution was based on standard deviation of observed values).

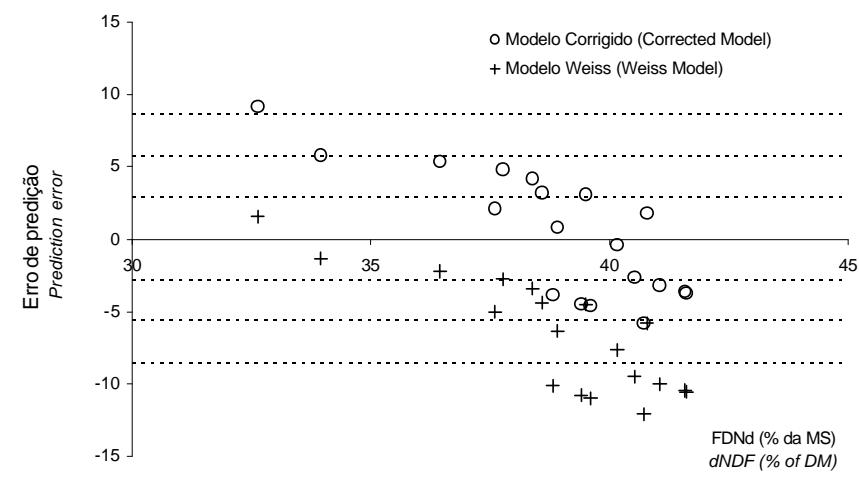

Figura 2 - Distribuição dos erros de predição (pontos percentuais) em função dos teores observados de FDN digestível (FDNd - \% da MS) para bovinos em crescimento (As linhas tracejadas indicam o afastamento em número de desvios-padrão calculados sobre os valores observados; $n=19$ ).

Figure 2 - Distribution of prediction errors (percent points) according to the observed contents of digestible NDF (dNDF - \% of DM) for growing cattle (The dashed lines indicate the distance in standard deviations from the observed values; $n=19$ ).
Em ambos os casos, verificou-se baixa contribuição do MaF ao QMEP (Tabelas 3 e 4). Este componente se relaciona à deficiência do modelo em simular a dimensão do afastamento de uma observação a partir da média aritmética de todas as observações da amostra (Kobaiashy \& Salam, 2000), indicando que ambos os modelos são igualmente eficientes no tocante a este quesito.

Verificou-se, no entanto, grande contribuição do MoF ao QMEP (Tabelas 2 e 3), destacando-se como componente quase exclusivo do QMEP do Modelo Corrigido para bovinos em crescimento. Este componente relaciona-se à capacidade do modelo em simular a direção do afastamento de uma observação a partir da média aritmética de todas as observações do conjunto de dados avaliado (Kobayashi \& Salan, 2000).

Mesmo com os ganhos obtidos com a adoção do Modelo Corrigido, a grande amplitude do MoF pode constituir limitação em sua aplicação. Ao menos em parte, as limitações quanto ao $\mathrm{MoF}$ dos valores simulados podem residir sobre a utilização da lignina como componente básico dos modelos para estimação da fração potencialmente digestível da FDN.

Estudos conduzidos em condições nacionais indicam correlações fracas ( $\mathrm{r}=0,1200$; Nunes et al., 2004b) a moderadas ( $r=0,6802$; Detmann et al., 2004) entre os teores de lignina e da fração indigestível da FDN, o que implica que estimativas gravimétricas do teor de lignina presente no alimento não permitem predizer com exatidão a dimensão da fração potencialmente digestível (ou indigestível) da FDN. Efeitos ambientais diversos exercem influências marcantes na estrutura química e no arranjo espacial do complexo lignina na parede celular vegetal (Van Soest, 1994). Assim, uma simples estimativa gravimétrica não permitiria estimar com acurácia a verdadeira ação inibitória da lignina sobre os carboidratos fibrosos dos alimentos.

Para que essa situação possa ser contornada, a obtenção de estimativas da fração potencialmente digestível da FDN poderia ser realizada por métodos biológicos (ex: via incubação ruminal in situ), que poderiam ser incorporados à rotina dos laboratórios de análises de alimentos, ampliando a eficiência do processo de predição.

Contudo, a despeito dessas limitações, o Modelo Corrigido, em comparação ao Modelo Weiss, por incorporar estimativas obtidas em condições brasileiras, permite a obtenção de estimativas mais exatas da fração efetivamente digestível da FDN, podendo constituir boa aproximação caso métodos biológicos não possam ser aplicados. 


\section{Conclusões}

A correção dos parâmetros relacionados ao fator de proteção da lignina sobre os carboidratos da parede celular vegetal e ao coeficiente de digestibilidade da porção potencialmente digestível da FDN sobre a equação adotada pelo NRC (2001) incrementa a eficiência de predição da fração digestível da FDN em condições brasileiras. Contudo, a utilização de métodos biológicos para estimação da porção potencialmente digestível da FDN pode conduzir a resultados mais verossímeis, tendo em vista a heterogeneidade da ação inibitória à degradação da parede celular vegetal por parte da lignina em condições tropicais.

\section{Literatura Citada}

AGRICULTURAL AND FOOD RESEARCH COUNCIL - AFRC. Energy and protein requirements of ruminants. Wallingford: CAB International, 1993. 159p.

ARROQUY, J.I.; COCHRAN, R.C.; NAGARAJA, T.G. et al. Effect of types of non-fiber carbohydrates on in vitro forage fiber digestion of low-quality grass hay. Animal Feed Science and Technology, v.120, n.2, p.93-106, 2005.

CAMPOS, P.R.S.S. Estimativas do valor energético de alguns volumosos e da digestibilidade da fibra em detergente neutro em ovinos. Viçosa, MG: Universidade Federal de Viçosa, 2004. 67p. Dissertação (Mestrado em Zootecnia) - Universidade Federal de Viçosa, 2004.

CHIZZOTTI, M.L. Avaliação da casca de algodão para novilhos de origem leiteira e determinação da excreção de cretinina e produção de proteína microbiana em novilhas e vacas. Viçosa, MG: Universidade Federal de Viçosa, 2004. 132p. Dissertação (Mestrado em Zootecnia) - Universidade Federal de Viçosa, 2004.

CONRAD, H.R.; WEISS, W.P.; ODWONGO, W.O. et al. Estimating net energy lactation from components of cell solubles and cell walls. Journal of Dairy Science, v.67, n.2, p.427-436, 1984.

COSTA, M.A.L; VALADARES FILHO, S.C.; VALADARES, R.F.D. et al. Validação das equações do NRC (2001) para predição do valor energético de alimentos em condições brasileiras. Revista Brasileira de Zootecnia, v.34, n.1, p.280-287, 2005.

DETMANN, E.; ZERVOUDAKIS, J.T.; CABRAL, L.S. et al. Validação de equações preditivas da fração indigestível da fibra em detergente neutro em gramíneas tropicais. Revista Brasileira de Zootecnia, v.33, n.6, p.1866-1875, 2004 (supl. 1).

DETMANN, E.; VALADARES FILHO, S.C.; CAMPOS, J.M.S. et al. Estimação da digestibilidade do extrato etéreo em ruminantes a partir dos teores dietéticos: desenvolvimento de um modelo em condições brasileiras. Revista Brasileira de Zootecnia, v.35, n.4, p.1469-1478, 2006a.

DETMANN, E.; PINA, D.S.; VALADARES FILHO, S.C. et al. Estimação da fração digestível da proteína bruta em dietas para bovinos em condições brasileiras. Revista Brasileira de Zootecnia, v.35, n.5, p.2101-2109, 2006b.

DETMANN, E.; VALADARES FILHO, S.C., HENRIQUES, L.T. et al. Estimação da digestibilidade dos carboidratos não-fibrosos em bovinos utilizando-se o conceito de entidade nutricional em condições brasileiras. Revista Brasileira de Zootecnia, v.35, n.4, p.1479-1486, 2006c.

DETMANN, E.; SOUZA, A.L.; GARCIA, R. et al. Avaliação do vício de "tempo longo" de indicadores internos em ensaio de digestão com ruminantes. Arquivo Brasileiro de Medicina Veterinária e Zootecnia, 2007 (no prelo).

FIGUEIREDO, D.M. Fontes de proteína em suplementos múltiplos para novilhas de corte em pastejo durante os períodos das águas e transição águas-seca. Viçosa, MG: Universidade Federal de Viçosa, 2005. 68p. Dissertação (Mestrado em Zootecnia) - Universidade Federal de Viçosa, 2005.

GUIMARÃES, A.L.R. Resíduo proveniente do beneficiamento do feijão (Phaseolus vulgaris L.) em rações para bovinos. Viçosa, MG: Universidade Federal de Viçosa, 2005. 92p. Tese (Doutorado em Zootecnia) - Universidade Federal de Viçosa, 2005.

JUNG, H.G.; DEETZ, D.A. Cell wall lignification and degradability. In: JUNG, H.G.; BUXTON, D.R.; HATFIELD, R.D. et al. (Eds.) Forage cell wall structure and digestibility. Madison: American Society of Agronomy, 1993. p.315-346.

KLEIBER, M. The fire of life: an introduction to animal energetics. 2.ed. New York: Robert E. Krieger Publishing Co., 1975. 453p.

KOBAYASHI, K.; SALAM, M.U. Comparing simulated and measured values using mean squared deviation and its components. Agronomy Journal, v.92, n.2, p.345-352, 2000.

LICITRA, G.; HERNANDEZ, T.M.; van SOEST, P.J. Standardization of procedures for nitrogen fractionation of ruminant feeds. Animal Feed Science and Technology, v.57, p.347-358, 1996.

LITTELL, R.C.; FREUND, R.J.; SPECTOR, P.C. SAS system for linear models. 3.ed. Cary: SAS Institute Inc., 1991. 329p.

MERCHEN, N.R. Digestion, absorption and excretion in ruminants. In: CHURCH, D.C. (Ed.) The ruminant animal: digestive physiology and nutrition. New Jersey: Prentice Hall, 1988. p.172-201.

MERTENS, D.R. Gravimetric determination of amylase-treated neutral detergent fiber in feeds with refluxing in beakers or crucibles: collaborative study. Journal of AOAC International, v.85, n.6, p.1217-1240, 2002.

MOULD, F.L.; ØRSKOV, E.R.; MANNS, O. Associative effects of mixed feeds. I. Effects of type and level of supplementation and the influence of the rumen $\mathrm{pH}$ on cellulolysis in vivo and dry matter digestion of various roughages. Animal Feed Science and Technology, v.10, p.15-30, 1983.

NATIONAL RESEARCH COUNCIL - NRC. Nutrient requirements of dairy cattle. 7.ed. Washington: Academic Press, 2001. 381p.

NUNES, L.B.M.; DETMANN, E.; COELHO DA SILVA, J.F. et al. Validação de equações preditivas do teor de fibra em detergente neutro indigestível em gramíneas tropicais: Sistema NRC (2001). In: ENCONTRO DE INICIAÇÃO CIENTÍFICA, 9., 2004, Campos dos Goytacazes. Anais... Campos dos Goytacazes: Universidade Estadual do Norte Fluminense, 2004a. (CD-ROM).

NUNES, L.B.M.; DETMANN, E.; COELHO DA SILVA, J.F. et al. Correlações lineares parciais entre componentes da parede celular em gramíneas tropicais cultivadas na Região Norte Fluminense. In: ENCONTRO DE INICIAÇÃO CIENTÍFICA, 9., 2004, Campos dos Goytacazes. Anais... Campos dos Goytacazes: Universidade Estadual do Norte Fluminense, 2004b. (CD-ROM).

OLIVEIRA, A.S. Casca de café ou casca de soja em substituição ao milho em dietas à base de cana-de-açúcar para vacas leiteiras. Viçosa, MG: Universidade Federal de Viçosa, 2005. 90p. Dissertação (Mestrado em Zootecnia) - Universidade Federal de Viçosa, 2005

ØRSKOV, E.R. The in situ technique for the estimation of forage degradability in ruminants. In: GIVENS, D.I.; OWEN, E.; AXFORD, R.F.E. et al. (Eds.) Forage evaluation in ruminant nutrition. London: CAB International, 2000. p.175-188.

PINA, D.S.; VALADARES FILHO, S.C.; VALADARES, R.F.D. et al. Consumo e digestibilidade aparente total dos nutrientes, produção e composição do leite de vacas alimentadas com dietas contendo diferentes fontes de proteína. Revista Brasileira de Zootecnia, v.35, n.4, p.1543-1551, 2006. 
PORTO, M.O. Suplementos múltiplos para recria terminação de bovinos em pastejo, durante o período das águas. Viçosa, MG: Universidade Federal de Viçosa, 2005. 99p. Dissertação (Mestrado em Zootecnia) - Universidade Federal de Viçosa, 2005.

ROCHA JR., V.R.; VALADARES FILHO, S.C.; BORGES, A.M. et al. Estimativa do valor energético dos alimentos e validação das equações propostas pelo NRC (2001). Revista Brasileira de Zootecnia, v.32, n.2, p.480-490, 2003.

SILVA, P.A. Valor energético do capim-elefante em diferentes idades de rebrota e estimativa da digestibilidade in vivo da fibra em detergente neutro. Viçosa, MG: Universidade Federal de Viçosa, 2004. 72p. Dissertação (Mestrado em Zootecnia) - Universidade Federal de Viçosa, 2004.

SNEDCOR, G.W.; COCHRAN, W.G. Statistical methods. 8.ed. Iowa: Iowa University Press, 1989. 503p.

Van SOEST, P.J. Nutritional ecology of the ruminant. Ithaca: Cornell University Press, 1994. 476p.
Van SOEST, P.J.; ROBERTSON, J.B. Analysis of forages and fibrous foods. Ithaca: Cornell University, 1985. 202p.

VIEIRA, R.A.M.; PEREIRA, J.C.; MALAFAIA, P.A.M. et al. The influence of elephantgrass (Pennisetum purpureum Schum., Mineiro variety) growth on the nutrient kinetics in the rumen. Animal Feed Science and Technology, v.67, n.2, p.151$161,1997$.

WALDO, D.R.; SMITH, L.W.; COX, E.L. Model of cellulose disappearance from the rumen. Journal of Dairy Science, v.55, n.1, p.125-129, 1972.

WEISS, W.P.; CONRAD, H.R.; St.PIERRE, N.R. A theoreticallybased model for predicting total digestible nutrient values of forage and concentrates. Animal Feed Science and Technology, v.39, p.95-110, 1992 